\title{
Concepções éticas a partir do pensamento de Henri Bergson. Ethical views from the thought of Henri Bergson
}

Adelmo José da Silva Universidade Federal de São João del-Rei

Departamento e Filosofia e Métodos adelmojs@ufsj.edu.b

A obra de Henri Bergson «As duas fontes da moral e da religião», possui uma marca de independência em relação aos assuntos outrora tratados por este pensador. É também uma obra que mereceu do autor uma atenção e dedicação especiais. É fato conhecido de que este filósofo não se deixou, em nenhum momento de sua elaboração, se tomar pela pressa e ansiedade de concluir a finalização e nem mesmo a conclusão das etapas da supracitada obra.

No período de elaboração até o momento de sua publicação, o filósofo francês dedicou-se a vários tipos de leitura e uma vasta documentação ligada ao assunto por ele tratado na referida obra. Assim, da redação até a publicação, demorou se muitos anos dedicados ao trabalho, cujo objetivo do autor era elaborar e apresentar algo inteiramente novo, interessante, pertinente e que servisse como colaboração à filosofia de forma geral.

Bergson desejou construir uma tese, demonstra la e abrir o espaço necessário para o debate e discussão em torno dos temas ali tratados. 
Alguns conceitos, ali presentes, já haviam sido anteriormente apresentados em outra obra de sua autoria, ou seja, na «Evolução criadora». E, em alguns momentos, o filósofo faz menção a esta obra, mas sempre feitas de forma explícita e, possivelmente, para não comprometer e deixar pairar dúvida sobre a sua verdadeira originalidade. Daí a importância de se considerar «As duas fontes da moral e da religião» não fracionada, mas sim na sua totalidade. E também considera la especialmente como uma obra que possui uma verdadeira autonomia em relação às demais. O mesmo se diz para a forma de se fazer a sua leitura, ou seja, considera la sob o ângulo da autonomia e independência em relação ao que outrora tinha por ele sido apresentado e discutido filosoficamente.

Ao fazer referencias à outra obra de sua autoria, «Evolução criadora», Henri Bergson mostra, de alguma maneira, um certo elo em termos de preocupação e método. O que em nada compromete a autonomia e independência de sua última obra. Observemos que dois conceitos centrais trabalhados por Bergson em a "Evolução criadora", a saber, duração e espaço, são marcados pela ausência de uma distinção. Isto sugere que, em sua última obra, parece nos que há uma retomada em termos metodológicos do que se enunciou na anterior obra acima mencionada. É como se Henri Bergson retomasse esta bipolaridade conceitual e desejasse dar prosseguimento à esta pesquisa, agora sob um novo foco de investigação filosófica.

Mas o fato é que «As duas fontes da moral e da religião» é uma obra que possui um diferencial marcante, pois se dirige diretamente à vida. Perguntamo nos, portanto, em que sentido isto se ocorre? Ora, ao tratar da moral, seja ela fechada ou aberta, Bergson sugere e remete à sua fundamentação. Seja ela fechada ou aberta, conforme sua designação, a mesma possui uma base que é onde a mesma se sustenta. Este 
fundamento para a moral em suas duas formas e modalidades, não se refere à razão.

O mesmo se diz em relação à sociedade que também não serve como fundamento para a moral. Ou seja, a racionalidade e a sociedade, de acordo com o pensamento de Henri Bergson, não servem com base para a moral em nenhuma de suas formas e modalidades. O fundamento, seja ele fechado ou aberto e que está subjacente à moralidade, ao invés de se referir à razão e mesmo à sociedade, se refere à vida mesma.

A creditamos que esta seja a tese principal defendida por Henri Bergson nesta obra, a saber, o que funda a moral e a religião, longe de ser a razão e a sociedade, não é outra coisa senão a própria vida, naquilo que existe de mais transcendente e absoluto.

Esta é uma colocação apresentada de imediato, sem que o mesmo tenha apresentado a questão supostamente vista como a mais importante.

Ao referir-se à vida, Bergson refere-se à questão dos sentido a ser lhe conferido. Não se trata somente da vida de uma maneira geral, mas, de forma mais precisa e particularizada. Diz respeito aos dois sentidos próprios a ela ligados. E que são apresentados, a partir desta última obra, como dois sentidos que se opõe de forma bastante clara e evidente. Cada um se dirige a uma direção nitidamente oposta em relação à outra.

Trata se de uma experiência imanente à vida e à historia dos homens de forma geral e que os colocam sempre numa posição em que os mesmos se percebem diante de situações inteiramente contrárias uma a outra.

Os dois sentidos possuem a capacidade de dar direcionamento à história, não apenas a dos homens em suas individualidades, mas a da história de maneira geral, da sociedade como um todo, da vida, bem como do universo. Porque o 
sentido se relaciona como o direcionamento, como o caminho indicado e a ser percorrido em direção a algum objetivo.

E aqui entra a experiência moral vivenciada pelos homens e pelas sociedades. E que está relacionada, à luz do pensamento de Bergson, com a vida em seus diversificados aspectos. É também critério fundamental, quando se trata de distinguir e evidenciar a diferenciação entre o fechado e o aberto no pensamento deste filósofo.

$\mathrm{O}$ fechado e o aberto, além de remontar à vida, como geralmente é percebido em um primeiro momento, deve ser visto como elementos eventualmente presente e norteadores da vida em um sentido e dimensão bastante particulares.

Isto sugere nos que, ao se colocar em contato com a experiência moral, a ação do homem que vive esta situação, pode ser identificada, a partir da compreensão e percepção destes dois conceitos antagônicos, o fechado e ao aberto.

A experiência moral é apresentada por este filósofo como o centro e referência de quase tudo que é mostrado em «As duas fontes da moral e da religião». Segundo ele, a moral que possui como base a abertura foi partilhada por grandes personagens que se fizeram presentes na história desde a sua antiguidade até os tempos atuais.

Trata se de uma experiência que encontra se presente em graus diferenciados nestes mesmos personagens históricos. Isto quer dizer, em alguns o comprometimento moral pautado na abertura se destaca mais em termos de presença, enquanto que em outros é menos evidente. Interessante observar também que sua presença é responsável pelos grandes atos praticados dentro da história humana. Outro aspecto igualmente merecedor de atenção é que a prática moral, onde subjaz a abertura, independe de uma vinculação religiosa, visto transcender inclusive esta experiência. 
Henri Bergson faz menção aos homens e mulheres que marcas positivas do ponto de vista moral, dentro da história. Menciona que tais personagens transformaram as situações sempre no sentido do aperfeiçoamento moral e ético.

Imaginamos que alguns fatores determinantes vieram contribuir decisivamente para a estruturação do pensamento de Henri Bergson. Dentre estes fatores externos e decisivos na estruturação de seu pensamento, apresentamos a primeira guerra mundial com suas consequências negativas e traumatizantes para toda a humanidade. Acreditamos, que em um primeiro momento, Bergson tenha acreditado e apostado na capacidade humana de perceber, intuitivamente, o males provocados por uma guerra daquela proporção. E que, mais que isto, ao perceber os males em função deste trágico acontecimento histórico, o homem pudesse intuir sobre a sua negatividade. Que pudesse avaliar as suas repercussões ruins para todos e ser capaz de assumir uma postura moral diante deste quadro. Em outras palavras, se por um lado o racionalismo pudesse apontar no sentido de não aprovar, mas pelo menos admitir a guerra, a intuição estaria ali para resguardar o bom senso e assegurar a importância dos acordos e da paz mundial. Isto considerando que a inteligência e a razão como elementos incapazes de esgotar a totalidade do real em termos de uma percepção total e absoluta da realidade. E, diante desta constatação de limitação da razão em termos de percepção total, estaria ali a intuição que, de uma força inexplicável do ponto de vista racional, seria capaz de transitar em um terreno nada familiar à razão e à inteligência, descortinando uma verdade inacessível por completo à racionalidade.

Esta era a grande aposta deste filósofo francês, apresentado de modo especial na sua obra «Evolução criadora». Assim 
Bergson pensou que, num determinado momento, aconteceria a percepção de que o uso somente da inteligência seria percebido como incapaz de encontrar uma solução para a situação de conflito e guerra. E que, no instante desta percepção, se encontraria um lugar a ser destinado à intuição, que , de forma mais abrangente, apontaria cominhos, até então, ainda não trilhados e que conduzissem a soluções pacíficas . Onde, deste modo, o simples uso da força bruta seria interpretado como ineficaz diante do grande desafio que era o de assegurar uma paz mundial e verdadeiramente duradoura.

Em termos concretos, Henri Bergson, apontava os males decorrentes de um eventual nacionalismo exacerbado. Insinuou que isto culminaria numa postura de fechamento em relação aos outros povos. Evidentemente, ele não se pronunciava em direção a uma completa ausência de nacionalismo. Esta não era a sua posição, mas sim a de que um nacionalismo levado ao seu extremo poderia gerar uma série de consequências negativas do ponto de vista da ética e da política. Especialmente se este nacionalismo exacerbado assumisse as feições de um chauvinismo e, consequentemente, se voltasse somente para si mesmo, fechando se completamente em relação às demais nações. Que impossibilitasse as relações e diálogos entre os diferentes povos.

Isto era considerado por Henri Bergson como um grave equívoco que poderia ser tomado como o fechamento tão abordado por ele em «As duas fontes da moral e da religião».

Deste modo, ele sinalizava sobre a necessidade de ir mais além das fronteiras e contemplasse o todo, a humanidade de um forma geral. Mostrava a inconveniência de uma atitude que viesse enclausurar as nações em si mesmas numa verdadeira endogenia política. 
Isto era apontado como uma possível explicação para os conflitos e indisposições internacionais que, quase sempre, acabavam desembocando em confrontos e guerras, muitas das quais com sérias implicações sociais e políticas para todos os povos.

Numa situação de endogenia política, uma nação envolvida neste quadro, não conseguiria enxergar além de sua próprias fronteiras. Não possuiria condições de visar senão o seu próprio interesse e bem estar. Ficaria impossibilitada de uma visão bem mais abrangente e de um horizonte maior. Precisamente aquela em que os povos são vistos como objetos de uma preocupação por parte de todas as comunidade políticas internacionais. E a questão do bem comum, enquanto aquilo que deva ser partilhado pela humanidade como um todo, ficaria seriamente comprometido e relegado a um outro plano que não fosse o primeiro.

A consideração bergsoniana é de que, aquilo que afeta a integridade do homem em sua constituição humana não diz respeito apenas ao seu país, ao seu grupo, à sua cultura, mas sim à humanidade de forma geral. Pois onde se encontra um só homem, ali está a humanidade em si representada. O mesmo vale dizer que, não contemplar os homens em suas individualidades, significaria negligenciar o aspecto maior. A saber, desconsiderar o conceito de humanidade enquanto totalidade dos homens dotados de direitos que devam ser considerados não apenas nacionais, mas sim direitos que se referem às dimensões internacionais e humanas.

Assim não deveria haver hostilidades e conflitos entre duas ou mais nações, se estas se compreendem como fazendo parte de um conjunto maior que é a humanidade. E o interesse de uma, mais do que um interesse ligado às fronteiras nacionalistas, deveria ser sob um ponto de vista moral, 
mais abrangente e estar ligada aos interesses de toda a humanidade. Isto se compara à inteligibilidade racional, onde não há como se pensar em oposição de verdades inteligíveis e racionais.

Uma possível atração por um nacionalismo fechado, portanto, deve ser considerado por Bergson como algo que não apresenta chances de colaboração universal. É visto por ele como algo não condizente com o eticamente desejável e que, eventualmente, possa representar riscos e ameaças para a comunidade universal em sua totalidade. Especialmente quando este chauvinismo se apresenta como absoluto, detentor da verdade inquestionável, sem mostrar chances de diálogo com outros povos. Segundo ele, uma nação fechada não reconhece o diferente em seu variados aspectos. Não abre as possibilidades de diálogo e volta se apenas para si mesma como se a outra realidade não existisse.

O não reconhecimento e a ausência desta visão universal levaria, quase sempre, a pensar o outro como sendo a ameaça. E, enquanto ameaça, acarretaria a ideia de ser algo que precisaria ser exterminada como forma de garantir a sua integridade endógena. É onde o extermínio é pensado como solução e garantia.

Por outro lado, Henri Bergson sugere a necessidade de se pensar, de modo especial, no patriotismo aberto e que se diferencia radicalmente do chauvinismo, do fechamento. Este, ao contrário, por não encontrar se fechado em si mesmo, considera a humanidade como um todo. O interesse pelo homem é sempre visto como um interesse ligado aos interesses da humanidade e, portanto, que deva ser considerado sempre.

Segundo Bergson, o caminho para se conseguir a tão sonhada paz universal passa, necessariamente, pela patriotismo aberto. E só uma adesão a este tipo de postura, levaria as pessoas 
a terem uma visão de humanidade que deva ser considerada e tratada com devidos cuidados e eticamente como um todo.

Mas, do ponto de vista histórico, o que se notou é que Henri Bergson, embora tenha sugerido e apostado seriamente na aceitação desta proposta, a guerra foi um fato. E este recebeu dele a consideração de que projetos políticos fechados em si mesmos acarretaram este episódio. Ao invés de se aderirem ao patriotismo aberto com seus benefícios e vantagens em todas as dimensões para a humanidade, as pessoas, especialmente as envolvidas naquele contexto de guerra, optavam pelo fechamento. O que acabava se desencadeando no amor exagerado à pátria, traduzido num radicalismo. $\mathrm{E}$ especialmente na desconsideração do que estivesse além das estreitas fronteiras nacionalistas. Com isto Bergson se deparou com um quadro histórico por ele diagnosticado como de nações fechadas em si mesmas e envolvidas num conflito universal. E onde estas não mostravam se outra atitude senão a de hostilidades mútuas e recíprocas.

Isto era visto por ele como um demonstração explícita e cabal do que foi apresentado em «As duas fontes da moral e da religião» e por ele conceituado como fechamento e em oposição à abertura. A consideração bergsoniana, portanto, é de que a hostilidade e o radicalismo resultantes do fechamento fizeram com que os dirigentes nacionalistas radicalizassem mais ainda o conflito.

Henri Bergson entendeu que, naquele momento específico de conflito universal, uma proposta como a apresentada por ele poderia pouparia a humanidade de uma série de sofrimentos e outras graves consequências.

Através de sua filosofia, pode ser observado que Bergson é um pensador que aposta na capacidade do homem de perceber, mesmo que seja de forma intuitiva, aquilo que se 
apresenta como o bom senso, o razoável e o sensato. Esta capacidade de percepção do razoável e sensato faz do homem um ser diferenciado. E a chance de percepção do que é sensato torna se ainda mais possível quando se relaciona com a moral pautada na abertura e que pode ser vivenciada pelo homem em diversos graus.

No entender deste pensador, a moralidade pautada na abertura é responsável por conduzir todas as ações humanas em direção ao bem. E isto numa tentativa de fazer acontecer a verdadeira libertação de tudo aquilo que aliena e estigmatiza a existência humana. E como esta moral transcende religiões, raças, cultura, há sempre a possibilidade de a mesma ser partilhado por todas as pessoas de forma indistinta.

Consequentemente, a abertura, onde se inclui o patriotismo aberto, é proposta para ser avaliada por todos os povos e com chances reais de ser aceita e assimilada indistintamente. E isto sem trazer eventuais prejuízos para esta ou aquela manifestação cultural ou convicção política.

Em se tratando especificamente sobre os dois sentido da vida para o homem, abertura e fechamento, Henri Bergson enfatiza a importância que deve ser dada à prática. Considera ser muito importante e possuir grande mérito a especulação filosófica, bem como a abstração. A filosofia é entendida como possuidora deste lado especulativo, onde se tem suas grandes vantagens.

Mas, igualmente é reconhecido por ele, que a filosofia não pode ficar limitada somente a este aspecto especulativo e abstrato. Ela deve se estender também para o lado prático da vida até mesmo como maneira de poder prestar a sua colaboração aos povos. Este pensador entende que a filosofia tem que provocar implicações na realidade e procurar efetuar mudanças na sociedade e nos indivíduos. Existe uma realidade social, 
política e econômica que carece de transformações, e , dentro deste quadro, a filosofia possui o seu papel e tem sempre algo a dizer para esta realidade carente de mudanças.

A partir da colocação acima, Henri Bergson sugere a vinculação entre a teoria e a prática em termos morais. Em «As duas fontes da moral e da religião», ele demonstra que uma moral aberta requer, numa linha de coerência, inspirar atos de abertura. Entre o pensar e o agir é preciso que se tenha uma coerência interna, gerando assim, ações voltadas para a abertura e liberdade.

A leitura que se faz da supracitada obra bergsoniana sugere esta aproximação entre o que se pensa e que se pratica. Donde se poder falar da experiência moral em consonância ou não com aquilo que se pensa e se pratica. Mas também é importante ressaltar a independência entre uma prática eticamente correta e uma eventual vinculação de fé a esta ou aquela religião. Mesmo porque a moralidade aberta, tão abordado por Bergson, não se associa se, necessariamente, às formas religiosas. Não há a necessidade de se professar um credo ou recitar uma profissão de fé para se ter a garantia de que seus atos morais serão sempre em direção ao bem. Para Bergson, é muito importante o agir. E este deve ser sempre pautado na busca do que é bem para a humanidade de forma a mais abrangente possível.

\section{Conclusão}

Henri Bergson escreve «As duas fontes da moral e da religião» conferindo à obra um aspecto simples. Também é onde o seu propósito moral é revelado no próprio título de sua obra, onde o mesmo deixa transparecer que seu objetivo que é trabalhar uma questão sempre discutida . 
A obra possui um aspecto de retomada de um assunto presente e discutido por vários outros pensadores da história da filosofia, ou seja, qual seria o fundamento da moral e especialmente o que a preside. Ao retomar o assunto, Bergson pretende ampliar esta discussão conferindo a ela aspectos novos e envolventes do ponto de vista filosófico, social e político. $\mathrm{O}$ propósito de ampliar e aprofundar a discussão se faz acompanhar de uma outra preocupação que é a de esclarecer conceitos essenciais ao tema. Parece nos também que a retomada está associada ao compromisso de fazer com que o tema tenha implicações diretas na realidade. E que não seja uma discussão desprovida e desvinculada de aplicações concretas na vida das pessoas, da sociedade, sob o ângulo social e político.

As categorias «fechado e aberto» são apresentadas e refletidas como sendo algo que, eventualmente, possam estar presente de forma velada, não necessariamente explícita, em práticas morais e políticas. E assim sendo, necessário se faz que, não somente seja diagnosticadas as presenças destas categorias de maneira implícitas, mas que uma posição seja tomada no sentido de salvaguardar a ética e a moral.

Consideramos ainda que, para Henri Bergson, mais significante que a distinção de que falamos acima, é uma outra que se faz presente até de certa forma sutil e que subjaz a esta, a saber, distinguir entre o fechado e o aberto. Este é o elemento por nós considerado essencial na compreensão do pensamento deste autor. Quer dizer, só é possível verificar a existência de dois tipos de moral quando se observa que, por detrás, encontra-se o fechado ou o aberto. Este seria o critério caracterizante e aplicado como método responsável pela distinção. 
Bibliografía

Adolphe, Lydie. (1946). La Philosophie Religieuse de Bergson. Paris: PUF.

Bachelard, Gaston. (1989). La Dialectique de la Durée. Paris: PUF. Benda, J. (1912). Le Bergsonisme ou une Philosophie de la Mobilité. Paris: Mercure de France.

Bergson, Henri. (1991). Essai sur les Données Immédiates de la Conscience; IN: Oeuvres. $5^{\mathrm{a}}$ édition. Paris: PUF, Édition du Centenaire.

Bergson, Henri. (1991a). La Pensée et le Mouvant; IN: Oeuvres. $5^{a}$ édition. Paris: PUF, Édition du Centeneire.

Bergson, Henri. (1991b). L'Énergie Spirituelle; IN: Oeuvres. $5^{a}$ édition. Paris: PUF, Édition du Centenaire.

Bergson, Henri. (1991c). Les Deux Sources de la Morale et de la Religion; IN: Oeuvres. $5^{a}$ édition. Paris: PUF, Édition du Centenaire.

Bergson, Henri. (1991d). L'Évolution Créatrice; In: Oeuvres. $5^{a}$ édition. Paris: PUF, Édition du Centenaire.

Bernard-Leroy, E. (1898), L'illusion de Fausse Reconnaissance: Contrubution à L'Étude des Conditions Psychologiques de la Reconnaissance des Souvenirs. Paris: Félix Alcan.

Bretonneau, G. (1975). Création et Valeurs Éthiques chez Bergson. Paris: Sedes.

Brochard, V. (1954). Études de Philosophie Ancienne et de Philosophie Moderne. Paris: Vrin.

Challaye, F. (1928). Bergson. Paris: Librairie Mellottée.

Chevalier, Jacques. (1948). Bergson. Paris: Plon.

Delattre, Floris et al. (1948). Les Études Bergsoniennes. Paris: Albin Michel.

Deleuze, Gilles. (1988). A Retum to Bergson, IN Bergsonism. New York: Zone Books. 
Férnart, M. (1936). Les Assertions Bergsoniennes. Paris: Vrin. Silva, Adelmo José. (2001). A relação entre a moral e o misticismo em Henri Bergson. Tese de doutorado em Filosofia. Rio de Janeiro: Universidade Gama Filho, 2001.

Silva, Adelmo José. (2001a). A fundamentação da moral em Bergson. Anais de Filosofia. (8), 45-56.

Silva, Adelmo José. (2004). O significado do misticismo no pensamento moral de Henri Bergson. Problemas e teorias da ética contemporânea. Porto Alegre: Edipucrs. 


\section{Resumo}

Para Bergson, as diversas formas de interpretar a moral e procurar traduzi-la na vida concreta de uma determinada comunidade ou grupo são sempre marcadas pela presença do aspecto fechado ou do aberto. De sorte que, antes de se perguntar pelo tipo de moral que é experimentada por um grupo ou pessoa, há de se perguntar, em primeiro lugar, pelo que está subjacente a ela, o aspecto fechado ou aberto. Isto equivale perguntar pela dimensão ética que preside determinada moral. Nosso objetivo é mostrar este aspecto do pensamento de Bergson no que se refere à moral e à ética e que faz com que o seu pensamento seja considerado de uma grande e significante atualidade. Pois não se trata de perguntar simplesmente pela forma de moral vigente, mas pelo que está presidindo as relações interpessoais e modos diversos de vida.

\section{Abstract}

For Bergson, the various forms of moral and interpret and translate it given concrete life or a community marked are semper group the presence open or closed. Before hair kind of morality that experienced by person or group, is ha of ask first hair is it underlies, closed or open is. It is equivalent ask the dimension presiding determined moral or ethics. Our target display this aspect of philosophy of Bergson do not have moral and ethical referral and that was that what makes his philosophy considered large and significant present. Is not only ask form of moral, but ask what is presiding interpersonal relationships and diverse lifestyles. 
Resumen

Para Bergson, las distintas formas de interpretar la moral y buscar traducirla en la vida concreta de una comunidad o grupo en particular se encuentran siempre marcadas por la presencia de aspecto cerrado o abierto. Así que, antes de pedir el tipo de moralidad que es experimentado por un grupo o una persona, en primer lugar, por detrás de ella, cerrado o aspecto abierto. Esto equivale a pedir a la dimensión ética que preside todo moral. Nuestro objetivo es mostrar a este aspecto del pensamiento de Bergson con respecto a la moral y la ética, y que hace que su pensamiento es considerado como un gran y significativo hoy. Porque no es simplemente pedir la forma de la moralidad actual, sino por lo que está presidiendo las relaciones interpersonales y las diferentes formas de vida

Palavras chaves: concepção; ética; moral e política. 